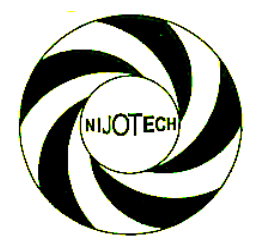

Nigerian Journal of Technology (NIJOTECH)

Vol. 36, No. 2, April 2017, pp. 496 - 504

Copyright(C) Faculty of Engineering, University of Nigeria, Nsukka

Print ISSN: 0331-8443, Electronic ISSN: 2467-8821

www.nijotech.com

http://dx.doi.org/10.4314/njt.v36i2.24

\title{
EVALUATION OF PAWPAW LEAVES EXTRACT AS ANTI-CORROSION AGENT FOR ALUMINIUM IN HYDROCHLORIC ACID MEDIUM
}

\author{
M. Omotioma ${ }^{1, *}$ and O. D. Onukwuli ${ }^{2}$ \\ 1 Dept. of Chemical Engr., EnUgu State University of SCI. And TeCh., ENUGU, EnUGU STATE NigERIA \\ 2 DEPARTMENT OF CHEMICAL ENGINEERING, NNAMDi AZIKIWE UnIVERSITY, AWKa,ANAMBRA STATE. NIGERIA
}

E-mail addresses: 1omorchem@yahoo.com2onukwuliod@yahoo.com

\begin{abstract}
Pawpaw leaves extract was examined as anti-corrosion agent for aluminium in hydrochloric acid medium. The extract and corrosion product were analyzed using Fourier transform infrared spectrophotometer (FTIR). Thermometric, gravimetric, potentiodynamic polarization and scanning electron microscopic methods were employed in the study. The inhibition efficiency was optimized using Response Surface Methodology (RSM) of Design Expert Software 9. Inhibitor concentration $(0.2 \mathrm{~g} / \mathrm{l}-1.0 \mathrm{~g} / \mathrm{I})$, temperature $(303 \mathrm{~K}-333 \mathrm{~K})$ and time (1hour - 5 hours) were the considered factors. It was revealed that stretched $\mathrm{C}-\mathrm{H}$ and $\mathrm{O}-\mathrm{H}$ functional groups were predominantly responsible for the corrosion inhibition process. The adsorption of the extract on the aluminium surface adhered to the mechanism of physical adsorption. $A$ quadratic model adequately described the inhibition process. Optimum inhibition efficiency of $80.58 \%$ was obtained at inhibitor concentration of $0.961 \mathrm{~g} / \mathrm{l}$, temperature of $311.459 \mathrm{~K}$ and time of $3.932 \mathrm{hrs}$. The extract is a mixed-type inhibitor that can control both cathodic and anodic corrosion.
\end{abstract}

Keywords: Aluminium, Anti-Corrosion, HCl, Pawpaw Leaves.

\section{INTRODUCTION}

Aluminium and its alloys are of great economic importance in the transportation and engineering industries. They are used as reaction vessels, pipes, machinery and chemical batteries because of their advantages; low cost, lightness and good corrosion resistance at moderate temperatures [1, 2, 3]. It has been reported that passive oxide film formed on aluminium surface is responsible for its resistance to corrosion, but the surface film is amphoteric and dissolves substantially when the metal is exposed to high concentrations of acids or basses [2, 4]. Aluminium dissolves readily in hydrochloric acid to form aluminium chloride and hydrogen. The reaction is more vigorous as the acid becomes hotter and more concentrated [5].

$$
2 \mathrm{AI}+6 \mathrm{HCI} \rightarrow 2 \mathrm{AICI}_{3}+3 \mathrm{H}_{2}
$$

Aluminium structure corrodes as a result of electrochemical reaction with its environment. It has been stated that corrosion is one of the major challenges facing oil and gas industries [6]. Pickling, descaling and cleaning are often carried out to prolong the life span of the aluminium structures. Acid medium such as $\mathrm{HCl}$ used for such maintenance operations often corrodes the structures. There is need to employ plant-based inhibitor of suitable inhibitive properties as additive in the maintenance operations.

Synthetic chemical substances have been used for the corrosion inhibition of aluminium in corrosive media. The inhibition effect of potassium iodate on the corrosion of aluminium in $\mathrm{HCl}$ has been reported [2]. Weight loss, polarization and impedance spectroscopy techniques were employed in the study. The potassium iodate was found to be a mixed type inhibitor with good inhibition efficiency. The experimental data were best fitted in Temkin adsorption isotherm. In alkaline solutions, the influence of three selected polyacrylic acids on the corrosion inhibition of aluminium was carried out [7]. The measurements were conducted under different conditions using chemical and electrochemical techniques, complemented with energy dispersive $x$-ray examinations of the electrode surface. The inhibition efficiencies of the inhibitors increased with increase in concentration, molecular weight and immersion time. Corrosion inhibition of aluminium in hydrochloric acid by anionic polyelectrolyte pectates as water-soluble natural polymer polysaccharide was studied [3]. Weight loss and gasometric techniques were used in the study. It was observed that inhibition efficiency increased with increase in inhibitor 
concentration and decreased with increase in temperature.

Due to environmental concern, eco-friendly inhibitors of plant origin are of great interest for corrosion control of metals in corrosive media. Effects of tobacco and kola tree extracts on the corrosion inhibition of aluminium alloy in sulphuric acid were investigated using gravimetric and metallographic methods [8]. It was observed that the corrosion inhibition was associated with the protective film provided on the aluminium alloy's surface by the complex chemical constituents of the extracts. In another work, inhibition effect of Dendrocalamus brandisii leaves extract on aluminium in $\mathrm{HCl}$ and $\mathrm{H}_{3} \mathrm{PO}_{4}$ solutions was reported [4]. The adsorption of the extract on aluminium surface obeys Langmuir isotherm in both acids. The Dendrocalamus brandisii leaves extract acted as cathodic inhibitor in $\mathrm{HCl}$. Furthermore, corrosion inhibition of mild steel in $\mathrm{HCl}$ with castor oil extract as inhibitor has been studied [9]. The experiment was carried out using thermometric, weight loss and potentiodynamic polarization methods, complemented with spectroscopic and microscopic analyses of the inhibition process. It was observed that there was a synergy among the functional groups of the extract in the corrosion inhibition process.

Research on pawpaw leaves extract is of great interest because it contains several alkaloids and other phytochemicals with important pharmaceutical and industrial applications [10]. The review of previous works showed that research gap exist in determining the optimum inhibition efficiency of pawpaw leaves extract as corrosion inhibitor of $\mathrm{Al}$ in $\mathrm{HCl}$ medium. There is need to determine the shifting mechanism of the extract's functional groups in the corrosion inhibition process. The aim of this work is to study pawpaw leaves extract as anti-corrosion agent for aluminium in hydrochloric acid medium.

\section{MATERIALS AND METHODS}

Analytical grade of $1.0 \mathrm{M} \mathrm{HCl}$ (May and Baker Ltd., Bagenmam, England) was used in this study. Leaves of pawpaw (Carica papaya) were obtained from Akpugo, Enugu State, Nigeria. Sheet of aluminium with chemical composition of Si $(0.25 \%)$, Fe (0.02\%), Zn (0.05\%), Mn (0.04\%) Mg (0.03\%), V (0.04\%), Ti (0.02\%), Cu (0.03\%), $\mathrm{Cr}(0.02 \%)$ and $\mathrm{Al}(99.5 \%)$, was cut into coupons $(5 \mathrm{~cm} \mathrm{x}$ $4 \mathrm{~cm}$ ). In the extraction of the pawpaw leaves extract and surface preparation of the aluminium, method used in previous study was adopted [9]. The pawpaw leaves were sun-dried for three days. The dried leaves were ground to increase the surface area and stored in closed containers. 30 grams of the ground plant leaves (fineness; particle size of $0.85 \mathrm{~mm}$ ) were measured and soaked in $1000 \mathrm{ml}$ of ethanol $(99.7 \% \mathrm{v} / \mathrm{v}$, Gunsgdong
Guandgua Chemical Factory Co. Ltd., Shatou, Guondghuo, China) for 48 hours. At the end of the 48 hours, the mixture was filtered. The filtrate obtained is a mixture of the extract and the ethanol. The pawpaw leaves extract obtained in ethanol solvent was concentrated by evaporating the ethanol from the mixture. The extract was used for the corrosion inhibition study. The $\mathrm{Al}$ coupons were cleaned followed by polishing with emery paper to expose shining polished surface. To remove any oil and organic impurities, the coupons were degreased with acetone and finally washed with distilled water, dried in air and then stored in desiccators. Accurate weight of each coupon was taken using electronic weighing balance and the initial weight was recorded. Fourier transform infrared spectrophotometer (SHIMADZU, Model: IR affinity - 1; S/N: A 2137470136 SI) was used to study the functional groups of the pure extract and corrosion product. Comparative analysis of various FTIR produced peaks were carried out to obtain the appropriate functional groups for the corrosion inhibition process. Thermometric, gravimetric and potentiodynamic polarization methods were used in the corrosion inhibition study. The inhibition efficiency was optimized using response surface methodology (RSM). Morphological observations of the corroded aluminium samples were carried out using scanning electron microscopy (SEM - model: Rhenom Prox, Phenom World Eindhoven, Netherlands).

\subsection{Thermometric Method of the Corrosion Inhibition Study}

The method of the thermometric measurements used by previous studies was adopted with slight modification $[11,12]$. In the previous works, thermometric experiments were carried out using a unit of thermometric flask. In this study, equipment of thermostat, thermometer and beaker were assembled for the experimental purpose. The measurements were carried using a thermostat set at $30{ }^{\circ} \mathrm{C}$. The temperatures of the system containing the aluminium were recorded regularly until a steady temperature value was obtained. The reaction number (RN) and inhibitor efficiency were evaluated using Equations (2) and (3) respectively.

$$
\begin{aligned}
& R N=\frac{T_{m}-T_{i}}{t} \\
& I E \%=\left(1-\frac{R N_{\text {add }}}{R N_{\text {free }}}\right) \times 100
\end{aligned}
$$

In (1) and (2), $\mathrm{T}_{\mathrm{m}}$ and $\mathrm{T}_{\mathrm{i}}$ are the maximum and initial temperatures $\left(\right.$ in ${ }^{0} \mathrm{C}$ ) respectively, and $\mathrm{t}$ is the time in minutes elapsed to reach $\mathrm{T}_{\mathrm{m}}, \mathrm{RN}_{\text {free }}$ and $\mathrm{RN}_{\text {add }}$ are the reaction numbers for the aluminium dissolution in free and inhibited $\mathrm{HCl}$ medium respectively. 


\subsection{Weight loss (Gravimetric) Method of the Corrosion Inhibition Study}

The variation of aluminium weight loss was monitored periodically at various temperatures and in $\mathrm{HCl}$ medium, in the absence and presence of various concentrations of the pawpaw extract. At the appropriate time, the $\mathrm{Al}$ samples were taken out, immersed in acetone, scrubbed with a bristle brush under running water, dried and reweighed. The $\mathrm{Al}$ weight loss was calculated in grammes as the difference between the initial weight and the weight after the removal of the corrosion product. The weight loss $(\Delta w)$, corrosion rate (CR), inhibition efficiency (IE) and degree of surface coverage were calculated using the Equations (4), (5), (6) and (7) respectively [9].

$$
\begin{gathered}
\Delta_{w}=w_{i}-w_{f} \\
C R=\frac{w_{i}-w_{f}}{A t} \\
I E \%=\frac{\omega_{0}-\omega_{1}}{\omega_{0}} * 100 \\
\theta=\frac{\omega_{0}-\omega_{1}}{\omega_{0}}
\end{gathered}
$$

Here $w_{i}$ and $w_{f}$ are the initial and final weight of $\mathrm{Al}$ samples respectively; $\omega_{1}$ and $\omega_{0}$ are the weight loss values in presence and absence of inhibitor, respectively. $A$ is the total area of the aluminium sample and $t$ is the immersion time.

Considering the corrosion rates of the aluminium at $\mathrm{T}_{1}$ and $T_{2}$ as $C_{1}$ and $C R_{2}$, the activation energy, $E_{a}$, was obtained using Equation (8) $[9,13,14,15]$.

$$
\ln \left({ }^{C R_{2}} / C R_{1}\right)=\left(E_{a / 2.303 R}\right)\left(\frac{1}{T_{1}}-\frac{1}{T_{2}}\right)
$$

The heat of adsorption $Q_{a d s}\left(\mathrm{kJmol}^{-1}\right)$ was calculated using Equation (9) $[14,16]$.

$$
Q_{a d s}=2.303 R\left[\log \left(\frac{\theta_{2}}{1-\theta_{2}}\right)-\log \left(\frac{\theta_{1}}{1-\theta_{1}}\right)\right] \times \frac{T_{2} \cdot T_{1}}{T_{2}-T_{1}}(9)
$$

In (9), $R$ is the gas constant, $\theta_{1}$ and $\theta_{2}$ are the degree of surface coverage at temperatures $\mathrm{T}_{1}$ and $\mathrm{T}_{2}$ respectively. Different adsorption isotherms were used to determine the mechanism of the adsorption of the extract on the metal surface $[4,9,14,17,18]$. Parameters of the Langmuir, Frumkin, Temkin and Flory-Huggins isotherms were obtained using Equations (10), (11), (12) and (13) respectively, while Equation (14) was used to determine the free energy of adsorption $\left(\Delta \mathrm{G}_{\text {ads }}\right)$.

$$
\begin{gathered}
\log \frac{C}{\theta}=\log C-\log K \\
\log \left((C) \times\left(\frac{\theta}{1-\theta}\right)\right)=2.303 \log K+2 \alpha \theta \\
\theta=-\frac{2.303 \log K}{2 a}-\frac{2.303 \log C}{2 a}
\end{gathered}
$$

$$
\begin{aligned}
\log \left(\frac{\theta}{\mathrm{C}}\right) & =\log K+x \log (1-\theta) \\
\Delta G_{\text {ads }} & =-2.303 R T \log (55.5 \mathrm{~K})
\end{aligned}
$$

Where $\mathrm{C}(\mathrm{g} / \mathrm{l})$ is the concentration of the inhibitor, $\mathrm{K}$ is the adsorption equilibrium constant and $\theta$ is the degree of surface coverage, $a$ is the attractive parameter, $\alpha$ is the lateral interaction term, $\mathrm{x}$ is the size parameter, $\mathrm{R}(8.314$ $\mathrm{kJ} / \mathrm{mol} . \mathrm{K})$ is the gas constant and $\mathrm{T}(\mathrm{K})$ is temperature. The inhibition efficiency was optimized using RSM of Design Expert Software 9. Central Composite Design (CCD), Face Center of the RSMwas used to design the experiment for the weight loss method. Inhibitor concentration, temperature and time were the considered factors of the study. The design matrix for the experiment is shown in Table 1. The RSM was used to analyze the responses. The ANOVA and graphical analyses of the inhibition efficiency were carried out. The mathematical models in terms of coded factors were obtained. The models in terms of coded factors were used to make predictions about the response for given levels of each factor. Optimum inhibition parameters were also obtained.

Table 1: Design matrix for the corrosion inhibition of Al in $\mathrm{HCl}$ by the pawpaw leaves extract.

\begin{tabular}{ccccc}
\hline Std & Run & $\begin{array}{c}\text { Factor 1; A: } \\
\text { Inhibitor } \\
\text { conc.(g/l) }\end{array}$ & $\begin{array}{c}\text { Factor 2; B: } \\
\text { Temperature (K) }\end{array}$ & $\begin{array}{c}\text { Factor 3; } \\
\text { C:Time (h) }\end{array}$ \\
\hline 14 & 1 & 0.6 & 318 & 5 \\
20 & 2 & 0.6 & 318 & 3 \\
13 & 3 & 0.6 & 318 & 1 \\
7 & 4 & 0.2 & 333 & 5 \\
12 & 5 & 0.6 & 333 & 3 \\
8 & 6 & 1 & 333 & 5 \\
5 & 7 & 0.2 & 303 & 5 \\
18 & 8 & 0.6 & 318 & 3 \\
3 & 9 & 0.2 & 333 & 1 \\
9 & 10 & 0.2 & 318 & 3 \\
1 & 11 & 0.2 & 303 & 1 \\
15 & 12 & 0.6 & 318 & 3 \\
6 & 13 & 1 & 303 & 5 \\
4 & 14 & 1 & 333 & 1 \\
11 & 15 & 0.6 & 303 & 3 \\
17 & 16 & 0.6 & 318 & 3 \\
16 & 17 & 0.6 & 318 & 3 \\
2 & 18 & 1 & 303 & 1 \\
10 & 19 & 1 & 318 & 3 \\
19 & 20 & 0.6 & 318 & 3 \\
\hline
\end{tabular}

\subsection{Potentiodynamic polarization Method of the Corrosion Inhibition Study}

Potentiodynamic polarization study was carried out using the method reported by previous studies $[19,20]$. The electrochemical test was conducted using a potentiostat / galvanost (263 Princeton, USA) electrochemical system workstation, with a conventional 
three-eletrode corrosion cell. A graphite rod and a saturated calomel electrode (SCE) were used as a counter and reference electrodes, respectively. An aluminium specimen fixed in epoxy resin with a surface area of $1 \mathrm{~cm}^{2}$ exposed to the test solution, served as the working electrode. Electrochemical measurements were carried out in aerated and unstirred solution at the end of $1800 \mathrm{~s}$ of immersion, which allowed the open circuit potential (OCP) to attain steady state. Temperature was fixed at $30 \pm 1{ }^{\circ} \mathrm{C}$. The inhibition efficiency was determined using Equation (15).

$$
I E \%=\frac{i_{c u}-i_{c i}}{i_{c u}} \times 100
$$

Where $i_{c u}$ and $i_{c i}$ are the corrosion current density values without and with inhibitor respectively.

\section{RESULTS AND DISCUSSION}

The FTIR spectra of the pure extract and corrosion product are presented in Figures (1) and (2). The peaks and their corresponding intensities represent the functional groups of the pawpaw leaves extract $[12,21$, 22]. The analysis of the extract revealed the presence of $\mathrm{C}-\mathrm{H}$ bend in plane, $\mathrm{C}=\mathrm{O}$ stretch, $\mathrm{C}-\mathrm{H}$ stretch and $\mathrm{O}-\mathrm{H}$ stretch (Table 2). Stretched $\mathrm{C}-\mathrm{H}$ at $2897 \mathrm{~cm}^{-1}$ peak shifted to $2866.14 \mathrm{~cm}^{-1}$. Also, stretched $0-\mathrm{H}$ at peak of $3668.5 \mathrm{~cm}^{-1}$ shifted to $3545.06 \mathrm{~cm}^{-1}$.It showed that C-H and $\mathrm{O}-\mathrm{H}$ functional groups were predominantly responsible for the corrosion inhibition process.

Table 3 presents data obtained by the thermometric method, where increase in inhibitor concentration increases the inhibition efficiency. High inhibition efficiency of $84.22 \%$ was obtained at inhibitor concentration of $1.0 \mathrm{~g} / \mathrm{l}$, indicating that pawpaw leaves extract is a strong inhibitor in the acid environment. The extract can be used for surface treatment of aluminium in contact with $\mathrm{HCl}$ environment. The results of the gravimetric method are shown in Table 4 . The $\mathrm{Al}$ weight loss and corrosion rate reduced with increase in concentration of the extract, but increased with increase in temperature. Highest inhibition efficiency of $80.12 \%$ was obtained at inhibitor concentration of $1.0 \mathrm{~g} / \mathrm{l}$, temperature of $303 \mathrm{~K}$ and time of $5 \mathrm{hrs}$. The inhibition efficiency and degree of surface coverage increased with increase in concentration of the extract, but decreased with increase in temperature.

The activation energy and heat of adsorption are shown in Table 5. The activation energy increased with increase in concentration. The negative sign of the heat of adsorption showed that the inhibitive process was an exothermic reaction. There was as spontaneous adsorption of the extract on the Al surface.

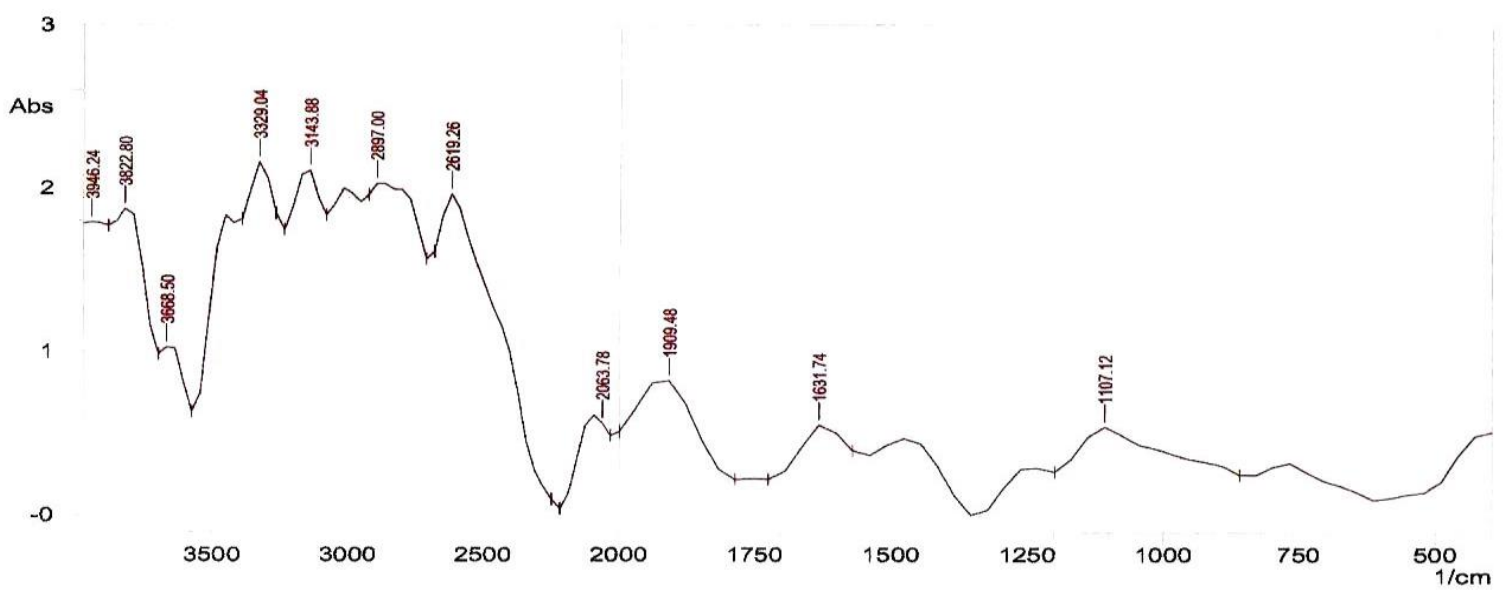

Figure 1: FTIR spectrum of the pawpaw leaves extract, absorbance (abs) versus wave number (1/cm).

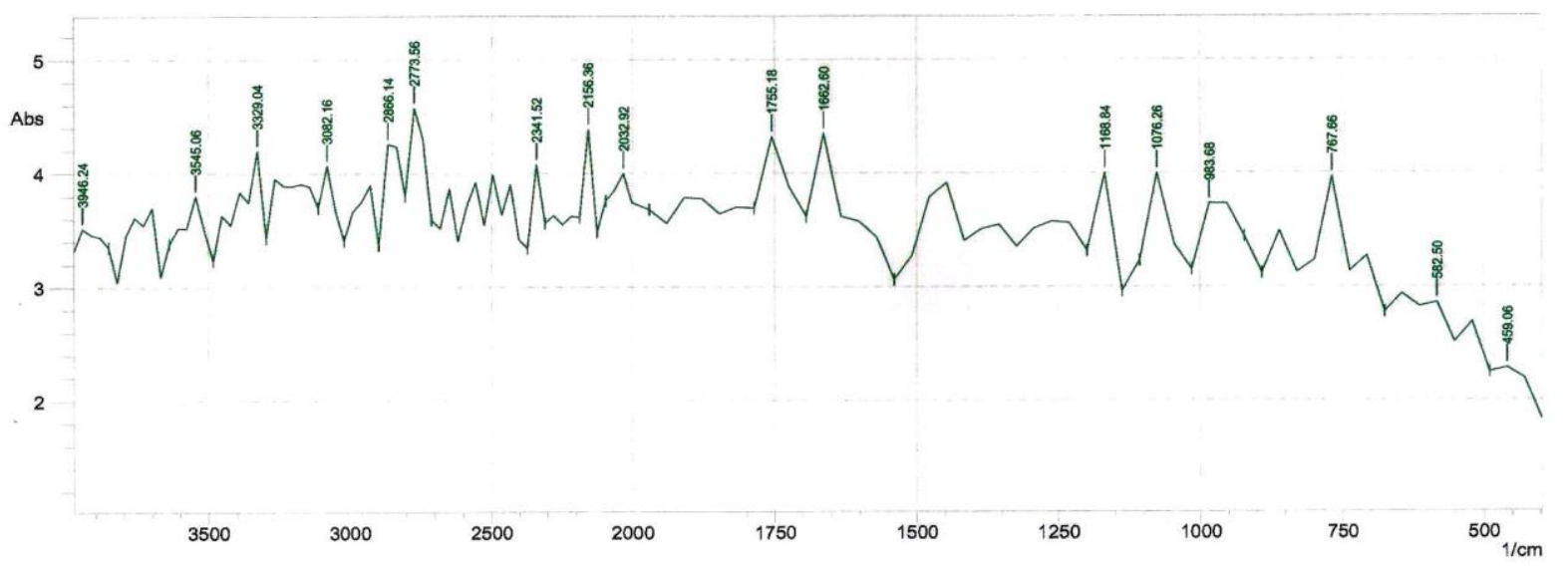

Figure 2: FTIR spectrum of the corrosion product, absorbance (abs) versus wave number (1/cm). 
Table 2: FTIR spectrum analysis of the pawpaw leaves and corrosion product

\begin{tabular}{c|c|c|c|c|c}
\hline \multicolumn{3}{|c|}{ Pawpaw leaves extract } & \multicolumn{3}{c}{ Corrosion product of Al in HCl (containing pawpaw leaves } \\
extract as inhibitor)
\end{tabular}

Table 3: Effect of concentration of the extract on the RN and IE of Al in HCl medium.

\begin{tabular}{lll}
\hline Inhibitor concentration, $\mathrm{g} / \mathrm{l}$ & Reaction number, $\mathrm{RN}\left({ }^{\circ} \mathrm{C} / \mathrm{min}.\right)$ & Inhibition efficiency, IE (\%) \\
\hline 0.0 & 0.1316 & --- \\
0.2 & 0.0636 & 51.64 \\
0.4 & 0.0485 & 63.17 \\
0.6 & 0.0260 & 80.22 \\
0.8 & 0.0249 & 81.08 \\
1.0 & 0.0208 & 84.22 \\
\hline
\end{tabular}

Table 4: Corrosion inhibition of Al in HCl with pawpaw leaves extract.

\begin{tabular}{|c|c|c|c|c|c|c|c|c|c|c|}
\hline \multirow{2}{*}{ Time, hr } & $0.2 \mathrm{~g} / \mathrm{l}$ & $0.4 \mathrm{~g} / \mathrm{l}$ & $0.6 \mathrm{~g} / \mathrm{l}$ & $0.8 \mathrm{~g} / \mathrm{l}$ & $1.0 \mathrm{~g} / \mathrm{l}$ & $0.2 \mathrm{~g} / \mathrm{l}$ & $0.4 \mathrm{~g} / \mathrm{l}$ & $0.6 \mathrm{~g} / \mathrm{l}$ & $0.8 \mathrm{~g} / \mathrm{l}$ & $1.0 \mathrm{~g} / \mathrm{l}$ \\
\hline & \multicolumn{5}{|c|}{ Weight loss $(\mathrm{g})$ at $303 \mathrm{~K}$} & \multicolumn{5}{|c|}{ Weight loss $(\mathrm{g})$ at $333 \mathrm{~K}$} \\
\hline 1 & 0.33 & 0.28 & 0.2 & 0.18 & 0.14 & 0.42 & 0.35 & 0.31 & 0.27 & 0.24 \\
\hline 3 & 0.76 & 0.51 & 0.31 & 0.3 & 0.28 & 0.92 & 0.64 & 0.53 & 0.523 & 0.52 \\
\hline \multirow[t]{2}{*}{5} & 0.863 & 0.530 & 0.340 & 0.320 & 0.290 & 0.980 & 0.690 & 0.610 & 0.590 & 0.587 \\
\hline & \multicolumn{5}{|c|}{$\mathrm{CR}\left(\mathrm{mg} / \mathrm{cm}^{2} \mathrm{hr}\right)$ at $303 \mathrm{~K}$} & \multicolumn{5}{|c|}{$\mathrm{CR}\left(\mathrm{mg} / \mathrm{cm}^{2} \mathrm{hr}\right)$ at $333 \mathrm{~K}$} \\
\hline 1 & 16.5 & 14 & 10 & 9 & 7 & 21 & 17.5 & 15.5 & 13.5 & 12 \\
\hline 3 & 12.67 & 8.5 & 5.17 & 5 & 4.67 & 15.33 & 10.67 & 8.83 & 8.72 & 8.67 \\
\hline \multirow[t]{2}{*}{5} & 8.63 & 5.30 & 3.40 & 3.20 & 2.90 & 9.80 & 6.90 & 6.10 & 5.90 & 5.87 \\
\hline & \multicolumn{5}{|c|}{ IE (\%) at $303 \mathrm{~K}$} & \multicolumn{5}{|c|}{ IE (\%) at $333 \mathrm{~K}$} \\
\hline 1 & 37.74 & 47.17 & 62.26 & 66.04 & 73.58 & 30.00 & 41.67 & 48.33 & 55.00 & 60,00 \\
\hline 3 & 39.68 & 59.52 & 75.40 & 76.19 & 77.78 & 34.75 & 54.61 & 62.41 & 62.91 & 63.12 \\
\hline \multirow[t]{2}{*}{5} & 46.40 & 67.08 & 78.89 & 80.12 & 81.99 & 44.00 & 60.57 & 65.14 & 66.29 & 66.46 \\
\hline & \multicolumn{5}{|c|}{ Degree of surface coverage $(\theta)$ at $303 \mathrm{~K}$} & \multicolumn{5}{|c|}{ Degree of surface coverage $(\theta)$ at $333 \mathrm{~K}$} \\
\hline 1 & 0.3774 & 0.4717 & 0.6226 & 0.6604 & 0.7358 & 0.3000 & 0.4167 & 0.4833 & 0.5500 & 0.6000 \\
\hline 3 & 0.3968 & 0.5952 & 0.7540 & 0.7619 & 0.7778 & 0.3475 & 0.5461 & 0.6241 & 0.6291 & 0.6312 \\
\hline 5 & 0.4640 & 0.6708 & 0.7889 & 0.8012 & 0.8199 & 0.4400 & 0.6057 & 0.6514 & 0.6629 & 0.6646 \\
\hline
\end{tabular}

Table 5: The activation energy and heat of adsorption for the corrosion inhibition process

\begin{tabular}{llll}
\hline Medium & $\begin{array}{l}\text { Conc. of } \\
\text { the extract } \\
(\mathrm{g} / \mathrm{l})\end{array}$ & $\begin{array}{l}\text { Activation } \\
\text { energy } \\
(\mathrm{kJ} / \mathrm{mol})\end{array}$ & $\begin{array}{l}\text { Heat of } \\
\text { adsorption, } \\
(\mathrm{kJ} / \mathrm{mol})\end{array}$ \\
\hline $\mathrm{HCl}$ & 0.2 & 8.187 & -2.710 \\
& 0.4 & 16.989 & -7.902 \\
& 0.6 & 37.641 & -19.368 \\
& 0.8 & 39.399 & -20.069 \\
& 1.0 & 45.410 & -23.264 \\
\hline
\end{tabular}

Adsorption parameters for the corrosion inhibition of aluminium in $\mathrm{HCl}$ by pawpaw leaves extract are shown in Table 6 . The values of free energy of adsorption $\left(\Delta \mathrm{G}_{\mathrm{ads}}\right)$ were less than the threshold value of $-40 \mathrm{~kJ} / \mathrm{mol}$, indicating adherence to physical adsorption. The dimensionless parameters, $\mathrm{R}^{2}$ (degree of determination), $\mathrm{K}$ (the adsorption equilibrium constant), $\alpha$ (lateral interaction term describing the interaction in adsorbed layer), a (the attractive parameter) and $\mathrm{x}$ (the size parameter, a measure of the number of adsorbed water molecules substituted by a given inhibitor molecule) 
were used to measure the fitness of the isotherms. The Langmuir isotherm has the highest values of $\mathrm{R}^{2}(0.9738$ and 0.9818 at $303 \mathrm{~K}$ and $333 \mathrm{~K}$ respectively), which showed strong adherence of the inhibition process to Langmuir adsorption isotherm. This is contrary to previous report [2], where the experimental data were best fitted in Temkin adsorption isotherm. The lateral interaction term $(\alpha)$ has positive values (1.9056 and 2.2576), suggesting attractive behaviour of the inhibitor on the Al surface. The attractive parameter (a) has negative values of -2.198 and -3.540 , indicating that repulsion exists in the adsorption layer. Parameter $\mathrm{x}$ has positive values of 0.9562 and 1.9994, which showed that the adsorbed species of the extract was bulky. These findings are in agreement with previous report (9).

Table 7 showed that the weight loss of the aluminium sample, corrosion rate and inhibition efficiency were concentration, temperature and time dependent. Inhibition efficiency increased with increase in concentration of the extract (inhibitor). Table 8 presents the analysis of variance (ANOVA).The degree of freedom (Df), Fisher test (F-test) and probability value ( $\mathrm{p}$-value) are $9,13.09$ and 0.0002 respectively. The $p$-value is less than 0.05 , which implied that the model is significant.

The analysis of inhibition efficiency of the pawpaw leaves extract (inhibitor) is presented in Figures (3). Plot of predicted versus actual inhibition efficiency was used to test the significance of the model. The predicted versus actual plot gave a linear graph. The graph (3-D surface plot) showed the relationship between the factors and response of the designed experiment. It showed that inhibition efficiency increased with increase in concentration, but decreased with increase in temperature.

Table 6: Adsorption parameters for the corrosion inhibition of Al in HCl by pawpaw leaves extract.

\begin{tabular}{|c|c|c|c|c|c|c|}
\hline $\begin{array}{l}\text { Adsorption } \\
\text { Isotherm }\end{array}$ & Temperature (K) & $\mathrm{R}^{2}$ & K & $\begin{array}{c}\Delta \mathrm{G}_{\text {ads }} \\
(\mathrm{kJ} / \mathrm{mol})\end{array}$ & \multicolumn{2}{|c|}{$\begin{array}{l}\text { Isotherm } \\
\text { property }\end{array}$} \\
\hline \multirow{2}{*}{$\begin{array}{l}\text { Langmuir } \\
\text { Isotherm }\end{array}$} & 303 & 0.9738 & 0.8784 & -9.8 & & \\
\hline & 333 & 0.9818 & 0.7071 & -10.2 & & \\
\hline \multirow{2}{*}{$\begin{array}{l}\text { Frumkin } \\
\text { Isotherm }\end{array}$} & 303 & 0.9802 & 0.0767 & -3.6 & \multirow{2}{*}{$\alpha$} & 1.9056 \\
\hline & 333 & 0.9538 & 0.0593 & -3.3 & & 2.2576 \\
\hline \multirow{2}{*}{$\begin{array}{l}\text { Temkim } \\
\text { Isotherm }\end{array}$} & 303 & 0.9440 & 43.16 & -10.6 & \multirow{2}{*}{$\mathrm{a}$} & -2.198 \\
\hline & 333 & 0.8870 & 138.68 & -24.8 & & -3.540 \\
\hline \multirow{2}{*}{$\begin{array}{l}\text { Flory-Huggins } \\
\text { Isotherm }\end{array}$} & 303 & 0.9650 & 4.8529 & -14.1 & \multirow{2}{*}{$\mathrm{x}$} & 0.9562 \\
\hline & 333 & 0.8249 & 7.6507 & -16.8 & & 1.9994 \\
\hline
\end{tabular}

Table 7: The RSM result of the corrosion inhibition of Al in HCl by pawpaw leaves extract

\begin{tabular}{|c|c|c|c|c|c|c|c|}
\hline Std & Run & $\begin{array}{l}\text { Factor 1; A: } \\
\text { Inhibitor } \\
\text { conc. }(\mathrm{g} / \mathrm{l}) \\
\end{array}$ & $\begin{array}{c}\text { Factor 2;B: } \\
\text { Temperature }(\mathrm{K})\end{array}$ & $\begin{array}{c}\text { Factor 3; } \\
\text { C:Time } \\
\text { (h) }\end{array}$ & $\begin{array}{l}\text { Response 1; } \\
\text { Weight loss } \\
\text { (g) }\end{array}$ & $\begin{array}{c}\text { Response } 2 ; \\
\text { Corrosion rate } \\
\left(\mathrm{mg} / \mathrm{cm}^{2} \mathrm{~h}\right)\end{array}$ & $\begin{array}{c}\text { Response 3; } \\
\text { Inhibition } \\
\text { efficiency (\%) }\end{array}$ \\
\hline 14 & 1 & 0.6 & 318 & 5 & 0.45 & 4.5 & 73.37 \\
\hline 20 & 2 & 0.6 & 318 & 3 & 0.36 & 6 & 71.43 \\
\hline 13 & 3 & 0.6 & 318 & 1 & 0.28 & 14 & 50.88 \\
\hline 7 & 4 & 0.2 & 333 & 5 & 0.98 & 9.8 & 44 \\
\hline 12 & 5 & 0.6 & 333 & 3 & 0.31 & 15.5 & 48.33 \\
\hline 8 & 6 & 1 & 333 & 5 & 0.587 & 5.87 & 66.46 \\
\hline 5 & 7 & 0.2 & 303 & 5 & 0.863 & 8.63 & 46.4 \\
\hline 18 & 8 & 0.6 & 318 & 3 & 0.36 & 6 & 71.43 \\
\hline 3 & 9 & 0.2 & 333 & 1 & 0.42 & 21 & 30 \\
\hline 9 & 10 & 0.2 & 318 & 3 & 0.86 & 14.33 & 36.3 \\
\hline 1 & 11 & 0.2 & 303 & 1 & 0.33 & 16.5 & 37.74 \\
\hline 15 & 12 & 0.6 & 318 & 3 & 0.36 & 6 & 71.43 \\
\hline 6 & 13 & 1 & 303 & 5 & 0.29 & 2.9 & 81.99 \\
\hline 4 & 14 & 1 & 333 & 1 & 0.24 & 12 & 60 \\
\hline 11 & 15 & 0.6 & 303 & 3 & 0.31 & 5.17 & 75.4 \\
\hline 17 & 16 & 0.6 & 318 & 3 & 0.36 & 6 & 71.43 \\
\hline 16 & 17 & 0.6 & 318 & 3 & 0.36 & 6 & 71.43 \\
\hline 2 & 18 & 1 & 303 & 1 & 0.14 & 7 & 73.58 \\
\hline 10 & 19 & 1 & 318 & 3 & 0.33 & 5.5 & 73.81 \\
\hline 19 & 20 & 0.6 & 318 & 3 & 0.36 & 6 & 71.43 \\
\hline
\end{tabular}


Table 8: ANOVA for the corrosion inhibition of Al in HCl by pawpaw leaves extract

\begin{tabular}{|c|c|c|c|c|c|c|}
\hline \multicolumn{7}{|c|}{ ANOVA for Response Surface Quadratic model; inhibition efficiency } \\
\hline \multicolumn{7}{|c|}{ Analysis of variance table [Partial sum of squares - Type III] } \\
\hline & Sum of & & Mean & $\mathrm{F}$ & p-value & \\
\hline Source & Squares & Df & Square & Value & Prob $>F$ & \\
\hline Model & 4315.30 & 9 & 479.48 & 13.09 & 0.0002 & Significant \\
\hline A-Inhibitor conc. & 2605.00 & 1 & 2605.00 & 71.09 & $<0.0001$ & \\
\hline B-Temperature & 439.83 & 1 & 439.83 & 12.00 & 0.0061 & \\
\hline C-Time & 360.24 & 1 & 360.24 & 9.83 & 0.0106 & \\
\hline $\mathrm{AB}$ & 44.98 & 1 & 44.98 & 1.23 & 0.2938 & \\
\hline $\mathrm{AC}$ & 7.59 & 1 & 7.59 & 0.21 & 0.6588 & \\
\hline $\mathrm{BC}$ & 1.44 & 1 & 1.44 & 0.039 & 0.8470 & \\
\hline$A^{\wedge} 2$ & 249.52 & 1 & 249.52 & 6.81 & 0.0261 & \\
\hline $\mathrm{B}^{\wedge} 2$ & 20.28 & 1 & 20.28 & 0.55 & 0.4740 & \\
\hline $\mathrm{C}^{\wedge} 2$ & 16.58 & 1 & 16.58 & 0.45 & 0.5164 & \\
\hline Residual & 366.41 & 10 & 36.64 & & & \\
\hline Lack of Fit & 366.41 & 5 & 73.28 & & & \\
\hline Pure Error & 0.000 & 5 & 0.000 & & & \\
\hline Cor Total & 4681.71 & 19 & & & & \\
\hline Std. Dev. & 6.05 & & \multicolumn{3}{|c|}{ R-Squared } & 0.9217 \\
\hline Mean & 61.34 & & \multicolumn{3}{|c|}{ Adj R-Squared } & 0.8513 \\
\hline C.V. $\%$ & 9.87 & & \multicolumn{3}{|c|}{ Pred R-Squared } & 0.4890 \\
\hline PRESS & 2392.57 & & \multicolumn{3}{|c|}{ Adeq Precision } & 13.445 \\
\hline
\end{tabular}

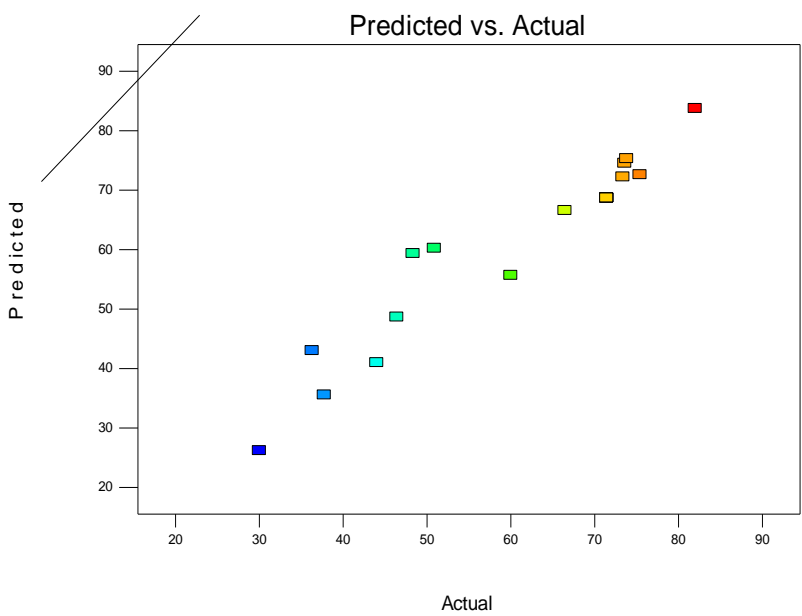

(a)

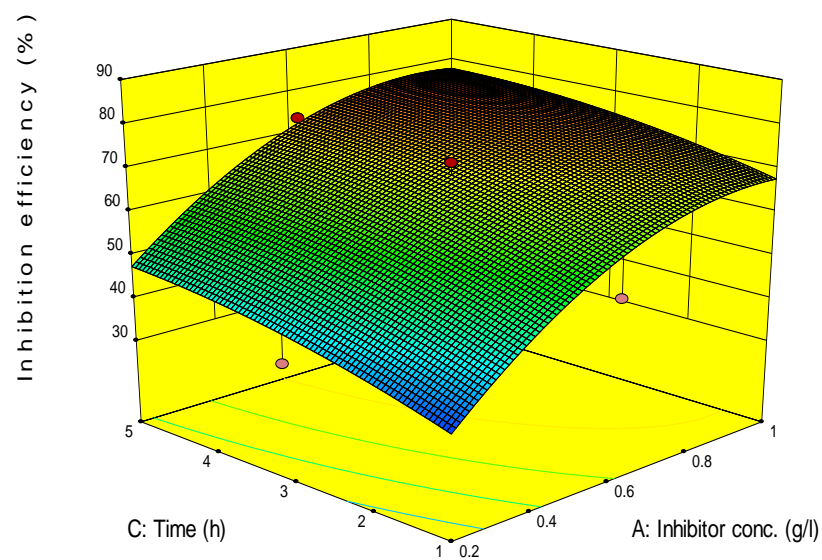

(c)

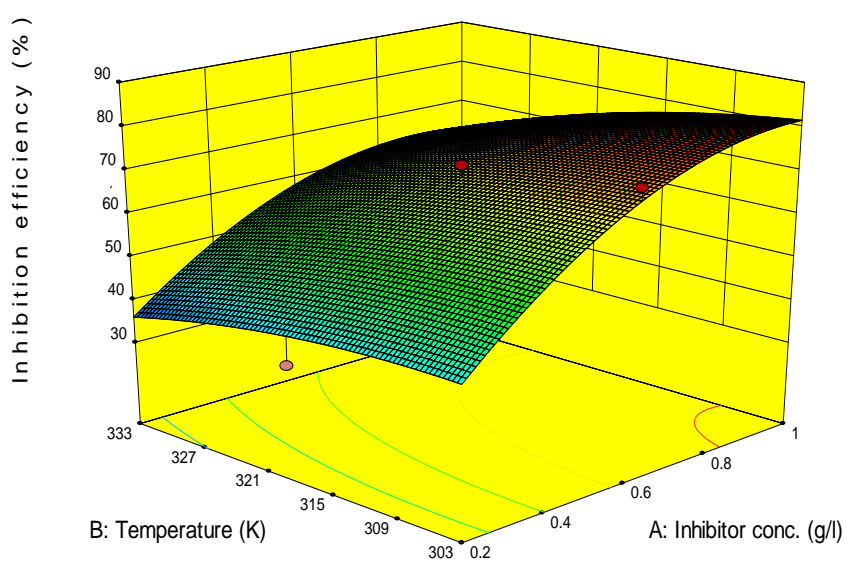

(b)

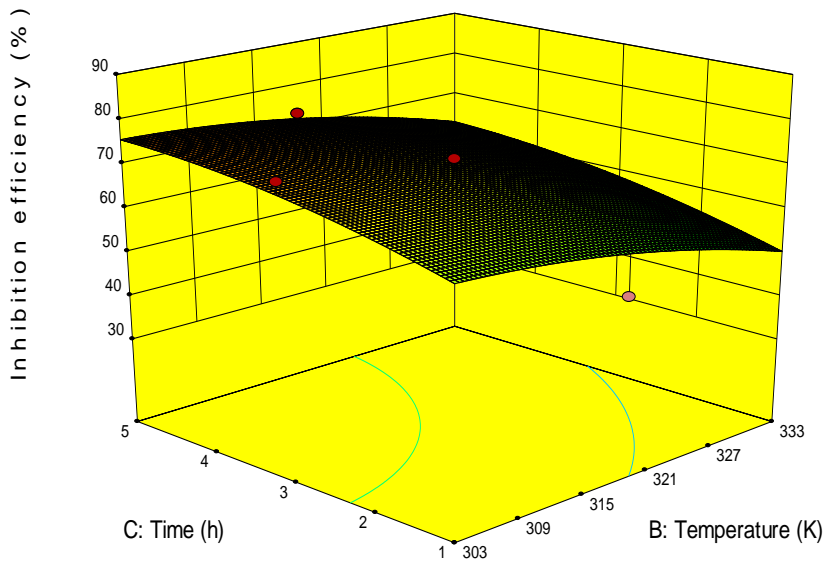

(d)

Figure 3: IE (\%) of pawpaw leaves extract as corrosion inhibitor of Al in HCl.

(a) Predicted versus Actual IE (\%), (b) IE (\%) versus inhibitor concentration and temperature (c) IE (\%) versus inhibitor concentration and time, d) IE (\%) versus temperature and time. 
Table 9: Optimum parameters for the corrosion inhibition process

\begin{tabular}{ccccc}
\hline \multicolumn{2}{c}{ Optimum parameter } & $\begin{array}{c}\text { Optimum inhibition } \\
\text { efficiency (\%) }\end{array}$ & $\begin{array}{c}\text { Measured inhibition } \\
\text { efficiency (\%) }\end{array}$ & $\begin{array}{c}\text { Percentage } \\
\text { variation (\%) }\end{array}$ \\
\hline Inhibitor conc. $(\mathrm{g} / \mathrm{l})$ & 0.961 & & & 1.27 \\
Temperature $(\mathrm{K})$ & 311.459 & 80.58 & 81.62 & \\
Time (hr) & 3.932 & & & \\
\hline
\end{tabular}

Considering general model terms, the model for the corrosion inhibition of $\mathrm{Al}$ in $\mathrm{HCl}$ by pawpaw leaves extract is expressed by Equation (16), while equation (17) is for its significant model terms.

$$
\begin{array}{r}
I E=68.69+16.14 C-6.63 T+6.00 t-2.37 C \times T \\
-0.97 C \times t+0.42 T \times t-9.53 C^{2} \\
-2.72 T^{2}-2.46 t^{2} \\
I E=68.69+16.14 C-6.63 T+6.00 t-9.53 C^{2}
\end{array}
$$

The inhibition efficiency is a function of inhibitor concentration $(\mathrm{C}, \mathrm{g} / \mathrm{l})$, temperature $(\mathrm{T}, \mathrm{K})$ and time $(\mathrm{t}$, $\mathrm{hr}$ ). The positive signs in the model signified synergistic effect, while the negative signs signified antagonistic effect. The highest power of at least one of the variables is 2 , which showed that the mathematical model is a quadratic equation.

As presented in (Table 9) optimum inhibition efficiency of $80.58 \%$ was obtained at inhibitor concentration of $0.961 \mathrm{~g} / \mathrm{l}$, temperature of $311.459 \mathrm{~K}$ and immersion time of 3.932 hrs. The result was validated with minor percentage deviation of $+1.27 \%$. It showed that response surface methodology of design expert software was adequate for the optimization of the inhibition process.

Table 10: The inhibition efficiency as determined by potentiodynamic polarization method

\begin{tabular}{llll}
\hline System & $\mathrm{E}_{\text {corr }}$ & $\mathrm{i}_{\text {corr }}$ & $\mathrm{IE} \mathrm{( \% )}$ \\
\hline $\mathrm{Al}[1 \mathrm{M} \mathrm{HCl}]$ & -664 & 266.7 & \\
+ 1g/L pawpaw leaves extract & -489.3 & 45.8 & 82.8 \\
\hline
\end{tabular}

The potentiodynamic polarization curve is presented in Figure4. The results provided the insight into the specific effects of the inhibitor on the anodic and cathodic corrosion reactions $[20,23]$. The extract was found to inhibit the corrosion of the aluminium in the $\mathrm{HCl}$ medium, affecting both the cathodic and anodic reactions. It acted as a mixed-type inhibitor. This is contrary to previous work [4], where the Dendrocalamus brandisii leaves extract acted as cathodic inhibitor in $\mathrm{HCl}$. High inhibition efficiency of $82.8 \%$ was obtained (Table 9). The mechanism of action of the inhibitor depended on the electron density and polarizability of the functional groups present in the molecule.

The micrographs of the corroded aluminium in $\mathrm{HCl}$ (in the presence and absence of the extract) are presented in Figure 5. The electron micrographs revealed that in the absence of inhibitor (a), the surface was strongly damaged owing to corrosion in the absence of the inhibitor, but in the presence of inhibitor (b), there is a much smaller damage on the surface. This is attributed to the formation of a good protective film on the metal surface

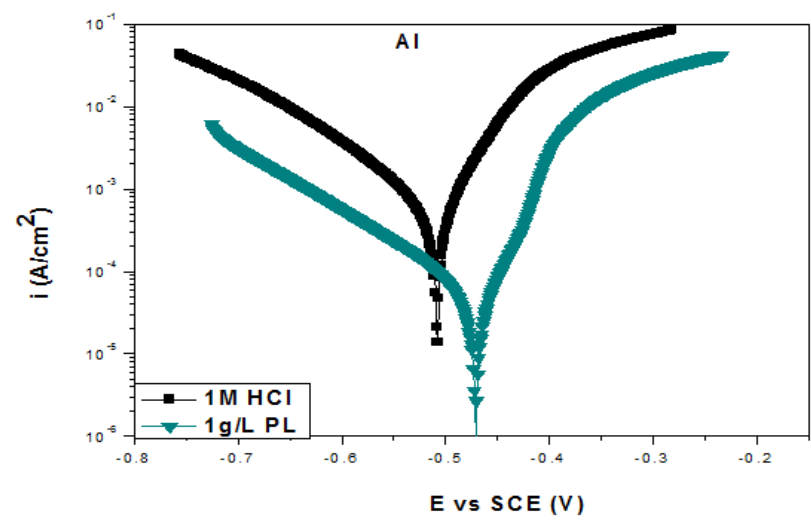

Figure 4: The polarization curves for Al in HCl in absence and presence of the pawpaw leaves (PL) extract.

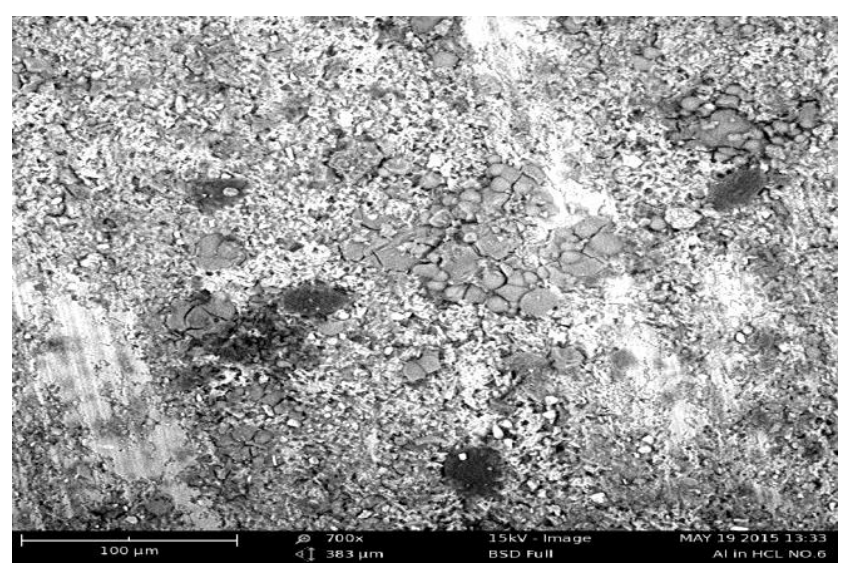

(a), without pawpaw leaves extract

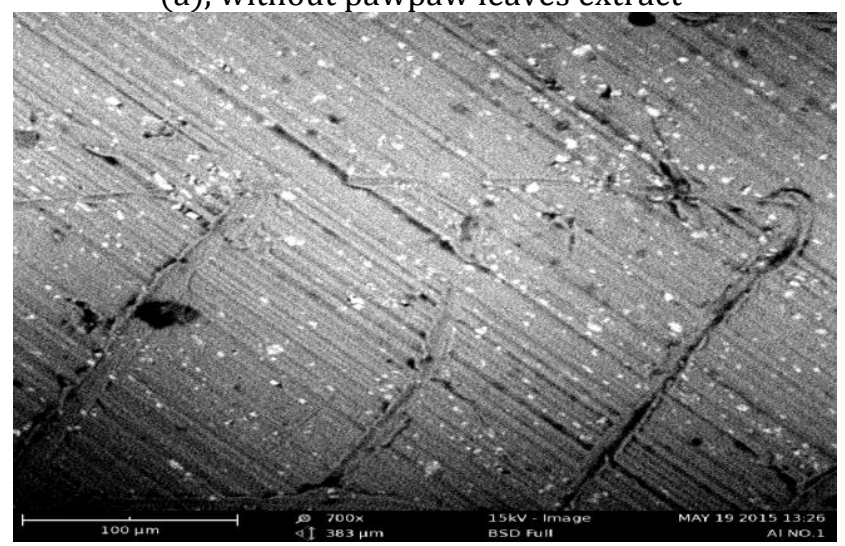

(b) with pawpaw leaves extract.

Figure 5: The micrograph of corroded Al surface in HCl. 


\section{CONCLUSION}

From the analysis of the shifting mechanism of the functional groups, stretched $\mathrm{C}-\mathrm{H}$ and $\mathrm{O}-\mathrm{H}$ functional groups were predominantly responsible for the corrosion inhibition process. The adsorption of the extract on the aluminium surface adhered to the mechanism of physical adsorption. The values of the isotherm properties showed attractive behaviour of the extract on the aluminium surface, repulsion in the adsorption layer and bulky adsorbed species of the extract. A quadratic model described the inhibition efficiency as a function of inhibitor concentration, temperature and immersion time. Optimum inhibition efficiency of $80.58 \%$ was obtained at inhibitor concentration of $0.961 \mathrm{~g} / \mathrm{l}$, temperature of $311.459 \mathrm{~K}$ and immersion time of $3.932 \mathrm{hrs}$. The extract is a mixed-type inhibitor that can control both cathodic and anodic corrosion. It is recommended that pawpaw leaves extract should be applied as additive for acidic cleaning of aluminium structures.

\section{REFERENCES}

[1] Kotz, J. C. and Treichel, P. Chemistry and Chemical Reactivity, $3^{\text {rd }}$ edition, Harcourt Brace Col. Publishers, New York, 1996.

[2] El-Maghraby, A. A. "Corrosion inhibition of aluminum in hydrochloric acid solution using potassium iodate inhibitor” , The Open Corrosion Journal, 2, 2009, 189 196.

[3] Refat, M. H. and Ishaq, A. Z. "Kinetics of corrosion inhibition of aluminium in acidic media by water - soluble natural polymeric pectates as aniomic polyelectrolyte inhibitors” ,Materials, 6, 2013, 2430 - 2451.

[4] Li, X. and Deng, S. "Inhibition effect of Dendrocalamus brandissi leaves extracts on aluminum in $\mathrm{HCl}, \mathrm{H}_{3} \mathrm{PO}_{4}$, Solutions” , Corrosion Science 65, 2012, 299 - 308.

[5] Aggarwal, 0. P. Engineering Chemistry, Kahanna Publishers, New Delhi, $3^{\text {rd }}$ Ed., 2010.

[6] Unueroh U., Omonria G., Efosa O. and Awotunde M. “ Pipeline Corrosion in Oil and Gas Industry: A case Study of NNPC/PPMC System. 2A Pipeline" , Nigerian Journal of Technology, 35 No 2, 2016, 317-320.

[7] Amin, M. A., El-Rehim S. S. A., El-Sherbini E. E. F., Hazzazi O. A. and Abbas M. N. ' 'Polyacrylic acid as a corrosion inhibitor for aluminium in weakly alkaline solutions. Part 1: Weight Loss, Polarization, Impedance EFM and EDX Studies' ' Corrosion Science, 51, 2009, 658-667.

[8] Loto, C. A. and Popoola, A. P. I. 'Plant extracts corrosion inhibition of Aluminum alloy in $\mathrm{H}_{2} \mathrm{SO}_{4}$. Canadian Journal of Pure and Applied Sciences. 6, (2), 2012, 1973 - 1980.

[9] Omotioma M. and Onukwuli O. D. "Corrosion inhibition of mild steel in $1.0 \mathrm{M} \mathrm{HCl}$ with castor oil extract as inhibitor” . Int. J. Chem. Sci., 14(1), 2016, 103-127.

[10] Sikandar, K, S., Tasveer, Z. B., Kanwal, N., Syed, A. G. and Shahana U. K. 'Qualitative phytochemical screening and antifungal activity of Carica papaya leaf extract against human and plant pathogenic fungi' .Int. J. Pharm., 4(7), 2013, 88-86.

[11] Mabrouk, E. M., Shokry, H. and Abu Al- Naja, K. M. “ Inhibition of aluminium corrosion in acid solution by mono- and bis-azo naphthylamine dyes, Part 1, Chem. Met. Alloys, 4, 2011, 98-106.

[12] Eddy, N. O., Ita, B. I., Dodo, S. N. and Paul, E. D. "Inhibitive and properties of ethanol extract of Hibiscus sabdariffa Calyx for the corrosion of mild steel in $0.1 \mathrm{M} \mathrm{HCl}$ " , Green Chemistry Letters and Reviews, 5 (1), 2012, 43 - 53.

[13] Octave, L. Chemical Reaction Engineering, Third Edition, John Wily and Sons, New York, 2003.

[14] Nwabanne, J. T. and Okafor, V. N. "Inhibition of the corrosion of Mild steel in medium by Vernonia amygdalina: Adsorption and Thermodynamic study". Journal of Emerging Trends in Engineering and Applied Science (JETEAS) 2(4), 2011, 619 - 625.

[15] Nnanna, L. A., Owate, I. O., Nwadiuko, O. C., Ekekwe, N. D. and Oji, W. J. "Adsorption and corrosion inhibition of Gnetum Africana leaves extract on carbon steel" International Journal of Materials and Chemistry, 3(1), 10-16. 2013.

[16] Orubite-Okorosaye, K. and Oforka, N. C. "Corrosion inhibition of zinc on $\mathrm{HCl}$ using Nypa fruticans Wurmb Extract and 1,5 biphenyl carbonzone", J. Appl. Sc. Environ. Mgt., 8(1), 57 - 61. 2004.

[17] Alinnor, I. J. and Ejikeme, P. M. “Corrosion inhibition of aluminum in acidic medium by different extracts of Osmium gratissium", American Chemical Science Journal 2(4), 122 - 135. 2012.

[18] Patel, N. S., Jauhariand, S., Mehta, G. N., Al-Deyeb, S. S., Warad, I. and Hammouti, B. "Mild steel corrosion inhibition by various plants extracts in $0.5 \mathrm{M}$ sulphuric acid” , Int. J. Electrochem. Sc., 8, 2635 - 2655. 2013.

[19] Oguzie, E. E., Enenebeaku, C. K., Akalezi, C. O., Okoro, S. C., Ayuk, A. A., Ejike E. N. "Adsorption and corrosioninhibiting effect of Dacryodis edulis extract on lowcarbon-steel corrosion in acidic media”, Journal of Colloid and Interface Science, 349, 283-292. 2010.

[20] Ihebrodike, M. M., Nwandu, M. C., Kelechukwu, B. O., Lebe, A. N., Maduabuchi, A. C., Eze, F. C. and Oguzie, E. E. Experimental and theoretical assessment of the inhibiting action of Aspilia Africana extract on corrosion aluminium alloy AA3003 in hydrochloric acid" , J. Mater Sci., 47, 2559-2572. 2011.

[21] Furniss, B. S., Hannaford, A. J., Smith, P. W. G. and Tatchell, A. R. Vogel's Textbook of Practical Organic Chemistry, $5^{\text {th }}$ edition, Longman Group, UK, 1989.

[22] Skoog, D., West, D. Holler, J. and Crouch, S. Fundamentals of Analytical Chemistry, 8 $8^{\text {th }}$ edition, India, 2004.

[23] Torres, V. V., Amado, R. S., Camila, F., Fernandez, T. L., Carlos, A. S. R., Torres, A. G. and Elian, D. "Inhibitory action of aqueous coffee ground extracts on the corrosion of carbon steel in $\mathrm{HCl}$ solution” , Corrosion Science, 53, 2385 - 2392. 2011. 